\title{
Estado de bem-estar social no Brasil: uma revisão ou a crise e o fim do "espírito de Dunquerque"
}

\author{
Claudio GuRgel ${ }^{1}$ \\ AgATHA JUSTEN ${ }^{1}$
}

${ }^{1}$ Universidade Federal Fluminense (UfF) / Programa de Pós-Graduação em Administração, Faculdade de AdministraçÃo E CIÊNCIAS CONTÁBEIS, NITERÓI - RJ, BRASIL

\begin{abstract}
Resumo
O objetivo deste artigo é retomar o debate sobre o estado de bem-estar social no Brasil para verificar em que medida o capitalismo brasileiro e seu Estado integraram o esforço de reforma social, que em plano mundial se realizou após a Segunda Guerra. Consideramos o caráter estrutural do welfare state: uma política social integrante do modo de produção em dado momento de seu desenvolvimento, quando as crises econômica, social e política, como uma unidade, se potencializam e exigem respostas reformistas e transformistas. Trabalhamos com a literatura clássica sobre o assunto, nacional e internacional. Além disso, consultamos documentos relativos à previdência, à assistência e ao contexto dos anos 1940-1950 no Brasil. Retornamos à literatura que debate o welfare state entre nós, com versões distintas e os dados do período, a fim de examinar quanto é possível afirmar que as mudanças no âmbito do Estado e das relações sociais de produção ora em curso são, na verdade, uma contraposição radical ao modelo criado pelo welfare state. Os resultados mostram que, no Brasil, se desenvolveram efetivamente as bases constitutivas desse modelo cujo formato refletiu nossas condições locais. Mas a unidade das causas que levaram às reformas sociais naquele momento carece hoje da sua dimensão política, sem a qual a dimensão econômica, exclusivamente, não é capaz de levar ao resgate da solidariedade e a políticas sociais universalistas.
\end{abstract}

Palavras-chave: Estado de bem-estar social. Crises. Reforma do Estado. Reformismo.

\section{Welfare state in Brazil: a review or the crisis and the end of the "Dunkirk spirit"}

\begin{abstract}
This article resumes the debate on the welfare state in Brazil to verify how the state and the capitalism developed in the country, were part of the social reform effort that emerged worldwide after the Second World War. The structural character of the welfare state may be considered as a social policy of the mode of production at a particular time of its development, when economic, social, and political crises were enhanced and required reformist and transformative responses. The study focused on national and international literature and examined documents related to social security, assistance, and the context of 1940s and 1950s Brazil. The analysis uses the literature discussing the Brazilian welfare state, its different versions and the data of that period to examine if the changes within the current state and social relations of production can be considered radical opposition to the welfare state model. The results show that in Brazil, the bases for the welfare state model were effectively developed in a format that reflected the local conditions. However, the research found that the unity of the causes that led to social reforms lacks political dimension nowadays, without which the economic dimension, exclusively, is not able to promote solidarity and social policies in their progressive concept.
\end{abstract}

Keywords: Welfare state. Crises. State reform. Reformism.

\section{Estado de bienestar social en Brasil: una revisión o la crisis y el fin del "espíritu de Dunquerque"}

\section{Resumen}

El objetivo de este artículo es recuperar el debate sobre el estado de bienestar social en Brasil para verificar hasta qué punto el capitalismo brasileño y su Estado han integrado el esfuerzo de reforma social, que en plan mundial se ha realizado tras la Segunda Gran Guerra. Partimos del presupuesto del carácter estructural del welfare state, integrante del modo de producción en dado momento de su desarrollo, cuando las crisis económica, social y política, como una unidad, se potencian y exigen respuestas reformistas y transformistas. Trabajamos con la literatura clásica sobre el tema, nacional e internacional. Además, consultamos documentos relativos a la seguridad social, a la asistencia y al contexto de los años 1940-1950 en Brasil. Regresamos a la literatura que debate el welfare state en Brasil, con autores con diferentes visiones y los datos del período para verificar cuánto es posible afirmar que los cambios en el ámbito del Estado y de las relaciones sociales de producción en curso constituyen, en realidad, una contraposición radical al modelo creado por el welfare state. Los resultados muestran que, en Brasil, se han desarrollado efectivamente las bases constitutivas de ese modelo cuyo formato reflejó nuestras condiciones locales. Concluimos que la unidad de causas que han llevado a las reformas sociales en aquel momento carece hoy de su dimensión política, sin la cual la dimensión económica, exclusivamente, no es capaz de llevar a la reforma en su concepto progresista.

Palabras clave: Estado de bienestar social. Crisis. Reforma del Estado. Reformismo. 


\section{INTRODUÇÃO}

A questão do estado de bem-estar social no Brasil tem ocupado autores com diferentes entendimentos, incluindo a dúvida sobre sua efetiva existência entre nós, em qualquer tempo histórico. Trata-se de um debate, devemos reconhecer, que em tempos passados teve maior relevo. Por que retornar a ele?

A ação social sempre esteve presente na história do capitalismo como um recurso de sociabilidade a que o modo de produção tem recorrido. O exemplo mais expressivo, ainda que reiterativo, é a Lei dos Pobres, em sua primeira edição, no século XVII. Apesar do reconhecimento dessa longeva preocupação social, não há como negar que a intensidade e a extensão de medidas voltadas ao abrandamento das condições de pobreza cresceram no século XX e mais ainda após a Grande Depressão. Estão, portanto, muito associadas ao que emerge na Inglaterra sob o título de welfare state.

Neste trabalho, tomamos como referência Esping-Andersen (1991) e Mishra (1990), para quem o welfare state se constituiu a partir da Segunda Grande Guerra e tem como característica distintiva, em relação às políticas sociais anteriores, o papel que o Estado, o mercado e a sociedade civil, integradamente, assumiram.

As ações sociais, a partir desse novo acordo, se inserem nos planos de sobrevivência do sistema ou, quando assim não se apresenta, em planos de aperfeiçoamento, sob a declaração da necessidade de superar limites do capitalismo, as "falhas do mercado". Isso se coloca no mesmo campo de preocupação do conhecido capítulo 24 da Teoria geral do emprego, do juro e da moeda, de Keynes, quando o economista inglês reconhece na economia de mercado a "incapacidade para garantir o pleno-emprego e a sua arbitrária e desigual distribuição da riqueza e dos rendimentos" (Keynes, 1964).

Essa consideração, porém, não significou para o capitalismo a desistência de se constituir em forma de vida social capaz de realizar as grandes bandeiras da Revolução Francesa. Em certo momento da história, as lideranças econômicas e políticas do projeto dominante encararam os problemas do capitalismo e olharam o desafio de um ponto de vista do poder do Estado sob seu controle. Contribuíram para isso: as crises econômicas, em sua definição restrita; a emergência da União Soviética e um conjunto de consequências disso que vão do efeito demonstração à maior politização do movimento operário; e as teorias da crise, em particular aquela referenciada na teoria dos ciclos, de Kondratiev (1979).

Entre 1873 e 1896, o capital viveu sua primeira grande crise, a Grande Depressão do século XIX, seguindo-se a Primeira Grande Guerra, de 1914 a 1919, de espectro europeu, e, mais adiante, a conhecida crise geral, ocorrida nos anos 1930, após o crash da bolsa de Nova York, em outubro de 1929. Em paralelo à crise do capitalismo, que em seu novo epicentro, os Estados Unidos, registrava milhares de falências e milhões de desempregados, a União Soviética crescia a taxas elevadas, impulsionada pelos seus dois primeiros planos quinquenais (Ellman, 1980).

Em passagem conhecida, Marx (2001) atribui as crises, em última instância, ao problema atávico do pauperismo e ao consequente baixo consumo. Em suas palavras,

a razão última de toda verdadeira crise é sempre a pobreza e a capacidade restringida de consumo das massas, com o que contrasta a tendência da produção capitalista a desenvolver as forças produtivas como se não existisse mais limite que a capacidade absoluta de consumo das massas (Marx, 2001, p. 455).

A crise dos anos 1930 produziu a ruptura teórico-ideológica com o pensamento clássico, seja nos planos econômico e político, seja organizacional. No plano econômico, isso foi o que fez Kalecki e Keynes, de pontos de partida diferentes, acusarem a insustentabilidade das teses clássicas de autorregulação em certas circunstâncias do desenvolvimento capitalista. Nas palavras de Keynes:

No que concerne a propensão a consumir, o Estado terá de exercer sobre ela uma influência orientadora através do seu sistema de impostos, fixando a taxa de juros e talvez ainda por outros meios [...] uma socialização algo ampla dos investimentos será o único meio de assegurar uma situação aproximada de pleno-emprego (Keynes, 1964, p. 356).

A crise também vai remeter à revisão política, especificamente sobre o papel do Estado, a qual se expressa de modo acentuado no New Deal, quando o governo Roosevelt mobiliza recursos públicos para sair da depressão. Ainda que haja os que negam o protagonismo do New Deal na erradicação da Grande Depressão (Friedman \& Schwartz, 1963) e o papel ativo do Estado 
como instrumento eficaz no combate às grandes crises (Grant, 2014), a verdade é que as estatísticas nacionais divulgadas por Kalecki (1978) mostram os efeitos positivos da intervenção estatal de Roosevelt.

É também nesse ambiente que avançam as ideias de um humanismo administrativo pragmático, mas que concretamente significa uma inflexão sob o peso dos sindicatos, do desemprego, do evidente desgaste do capitalismo e de movimentos civilizatórios religiosos e laicos. É finalmente nesse contexto que se configuram iniciativas no plano social, a forma mais explícita de a sociedade se dizer efetivamente preocupada em responder aos desafios deixados pelos escombros da crise e da guerra - desafios que não se limitavam a reerguer o patrimônio físico, e sim, sobretudo, a reerguer o pretendido patrimônio ético do capitalismo.

O avanço das ideias críticas em relação ao passado clássico, como reflexo do continuado embate econômico, teórico e político, ganha impulso com a derrota fascista e nazista, na Segunda Grande Guerra, e vai gerar, entre outras iniciativas, aquela que se tornou paradigma de uma nova regulação: o welfare state.

O estado de bem-estar social é, portanto, o produto de uma época em que se tentou construir, sobre as lições da Grande Depressão e as pedras do Reich de Mil Anos, a eternidade do capitalismo, sem crises e sem guerra. Um tempo em que as determinações econômicas e políticas criaram o contexto a que Wolff e Oliveira se referem em seu artigo "O 'espírito de Dunquerque' e o NHS inglês: teoria, história e evidências". O texto é uma alusão, como dizem os autores, "ao esforço nacional para resgatar as tropas britânicas encurraladas em uma faixa cada vez mais estreita na região de Dunquerque, na costa francesa", em 1940 (Wolff \& Oliveira, 2017, p. 206). Ali, em quase dez dias, 400 mil homens foram retirados com vida, tendo a ajuda de civis de todos os credos, raças e rendas. Uma epopeia levada ao cinema sob o título Dunkirk e que teve no protagonista, o ator Fionn Whitehead, uma ilustrativa definição: "O espírito de Dunquerque é a união das pessoas para lidar com uma crise".

Tratava-se do pós-Depressão dos anos 1930 e do pós-Guerra, um ambiente de renascimento que mereceu de Santos o comentário de que,

neste mundo de pós-guerra, a paz havia sido produto de um vasto movimento progressista mundial. Os aliados impuseram a democracia sobre o nazi-fascismo, os princípios de uma ordem social onde a soberania nacional, a democracia e a justiça social e a confiança na unidade do gênero humano serviam de princípios comuns para reordenar o mundo. O pleno emprego, o bem-estar econômico, o desenvolvimento e o crescimento econômico passavam a ser ideias universais (Santos, 2004, p. 156).

Por isso, não deixa de ser estranho que se pretenda isolar o Brasil desse cenário. Ainda que não o welfare state de Lord Beveridge, é de supor que algo semelhante tenha feito parte das conjeturas brasileiras.

O objetivo deste texto é, portanto, retomar o debate sobre o estado de bem-estar social no Brasil, partindo da acumulação já existente e acrescentando elementos que podem demonstrar como a burguesia brasileira e seu Estado também integraram o esforço de revolução passiva, não jacobina, que em plano mundial se realizou após a Segunda Grande Guerra. Queremos, com isso, afirmar o caráter estrutural do welfare state, que foi a resposta reformista e transformista-para recorrer à categoria de Gramsci (2007) - quando as crises econômica, social e política se potencializaram e assim o exigiram.

A necessidade de retomar esse tema se dá pelas reformas estruturais que estão sendo implementadas pelos Estados nacionais e suas administrações públicas como resposta à crise em curso, a exemplo do que tem ocorrido, em diferentes países e continentes, a partir dos anos 1980 (Jansen-Ferreira \& Mendes, 2018; Pastor-Seller, Verde-Diego \& Lima-Fernández, 2019; Stein, 2017). São reformas no plano social e trabalhista que limitam o provimento e o acesso a serviços públicos, que nos sugerem questionar que direitos são esses e porque eles surgiram em nosso país. A afirmação de que o welfare state também chegou ao Brasil nos permite entender o sentido e a amplitude das mudanças pelas quais passamos.

Em outras palavras, pretende-se apontar para um significado discreto, mas importante, desse debate, que consiste em reconhecer que políticas públicas em diversas áreas - da alimentação ao transporte - existiram, e seu esmaecimento se inscreve entre os déficits sociais da contemporaneidade, consequências práticas negativas da radicalidade da crise que vivemos. Voltar a refletir sobre essas circunstâncias ajuda a responder ao apelo de Kerstenetzky e Guedes (2018), quando dizem que "o welfare state resiste, mas precisa de reforços se o objetivo for colocar desigualdade e pobreza sob controle". De igual modo, contribui para recolocar a possibilidade de uma política econômica em que o social não seja um objeto à parte, e sim parte do objeto. 
Isto é, dizer, como Draibe e Henrique, que "as políticas sociais têm um papel central tanto na estratégia de redistribuição de renda quanto na promoção de uma recuperação econômica sustentada" (Draibe \& Henrique, 1988, s.p.).

Para esta revisão, trabalhamos com a literatura clássica sobre o assunto, tanto de autores estrangeiros, como brasileiros. Além disso, consultamos documentos publicados por fontes institucionais que produziram informações pertinentes à previdência, à assistência e ao próprio momento histórico vivido entre os anos 1940 e 1950. Incluímos textos novos que apontam para a atualidade do tema - aspecto que se destaca após a pandemia que recentemente abalou o mundo. No caso dos documentos que recuperam a Carta da Paz Social e a Conferência de Teresópolis, peças importantes na comprovação do envolvimento do empresariado brasileiro com o projeto social em evidência, lançamos mão de textos das próprias entidades patronais. Procuramos nos ater ao período próximo do lançamento e à aprovação do Plano Beveridge para situar as iniciativas brasileiras no mesmo "espírito de Dunquerque" que à época inspirou a iniciativa inglesa.

\section{O DEBATE}

O estado de bem-estar social (Ebes), em termos gerais, pode ser definido como "responsabilidade estatal no sentido de garantir o bem-estar básico dos cidadãos", tendo em conta, porém, que "não pode ser compreendido apenas em termos de direitos e garantias. Também precisamos considerar de que forma as atividades estatais se entrelaçam com o papel do mercado e da família em termos de provisão social” (Esping-Andersen, 1991, p. 99). Isso significa dizer que direitos e garantias já haviam sido tratados anteriormente, em formas de assistência do Estado. O que distingue essa forma que se configura no pós-Segunda Grande Guerra é o caráter solidário das três esferas da vida social, que se entrelaçam para promover esses direitos e garantias, o que de certo modo representa a hegemonia da social-democracia, lato sensu.

A construção a que se procedeu naquela época foi de natureza solidária, compreendendo o fenômeno a que se referem Santos (2004) e outros autores quando falam do sentimento de paz e colaboração que emergiu ao fim da guerra. Ainda que tenha sido pouco duradoura, a aliança construída para enfrentar o fascismo parece ter se estendido por alguns anos além dos conflitos e, junto com outros fatores intervenientes, deixado a herança necessária, a qual inclui a ONU - como símbolo-, o fordismo, o keynesianismo e o welfare state como referências públicas e privadas. Entre os fatores intervenientes, vale relembrar, estão a disputa de projetos econômico, político e ideológico, entre os dois blocos da Guerra Fria, e a convicção generalizada de que havia de fato a necessidade de manter o nível do consumo global e o pleno emprego para evitar as crises e subsidiariamente amenizar os conflitos sociais.

No caso brasileiro, alguns autores rejeitam a ideia de que aqui ocorreu welfare state. Por variadas razões, que muitas vezes são comparadas com o caso inglês, esses autores ou negam pela ausência de plenitude, como é o caso de Silva (2011), ou simplesmente negam que tenha havido, como Streck e Morais (2006). Segundo Silva (2011), "não houve um estado de bem-estar social no Brasil, considerando as características das políticas sociais nacionais já indicadas, as quais estavam constantemente relegadas ao segundo plano" (Silva, 2011, p. 31). Na mesma linha, Piana (2009) argumenta que "nos chamados países pobres e dependentes da América Latina, especialmente no Brasil, nunca ocorreu a garantia do bem-estar da população por meio da universalização de direitos e serviços públicos de qualidade" (Silva, 2011, p. 31). Faleiros (1991) concorda com essa ideia, ao comentar que "nos países pobres periféricos não existe o Welfare State nem um pleno keynesianismo em política. Devido à profunda desigualdade de classes, as políticas sociais não são de acesso universal" (Faleiros, 1991, p. 28).

De modo tão direto quanto Silva, Streck e Morais (2006) dizem que "em nosso país, as promessas da modernidade ainda não se realizaram [...] é evidente, pois, que em países como o Brasil [...] o Estado Social não existiu" (Silva, Streck \& Morais, 2006, p. 84). Mais recentemente, Soares (2020) reafirma tal posição, comentando que "no Brasil, país de profunda desigualdade social, o estado de bem-estar social é questionável, dado a manutenção da marginalização de comunidades negras, indígenas e pobres" (Soares, 2020, p. 3).

Outros autores, contudo, como Maria Lúcia Werneck Vianna (1991), Sônia Draibe (1993), Wanderley Guilherme dos Santos (1979), Sônia Fleury (1985) e, mais recentemente, Lenaura Lobato (2016), conduzem essa complexa discussão de modo diferente. Ademais, Luís Fiori (1997), em seu conhecido artigo "Estado de bem-estar social: padrões e crises", admite a 
hipótese do welfare state no Brasil, ainda que classifique o modelo brasileiro como meritocrático, utilizando as tipologias de Esping-Andersen e Titmuss.

Para melhor compreensão, Esping-Andersen (1991) e Titmuss (1963), citados por Fiori, oferecem uma taxonomia do estado de bem-estar social que leva o debate para um plano diretamente determinado por critérios e amplitude de acesso a direitos e garantias. Essa tipologia é usada por Fiori para situar sua posição em face do debate que ora retomamos - daí considerarmos que trazer Fiori para iniciar a apresentação dos autores que compreendem a possibilidade do welfare state no Brasil seja a solução mais econômica que se nos apresenta.

Ele nos expõe as tipologias de Titmuss e Esping-Andersen, como segue:

i. "The residual welfare model of social policy", o padrão ou modelo residual, "onde a política social intervém ex-post. e possui o caráter temporalmente limitado". Seria o caso contemporâneo dos Estados Unidos. ii. "The industrial achievement performance model of social policy", em geral traduzido como modelo ou padrão meritocrático-particularista, onde a política social intervém apenas para corrigir a ação do mercado. "O sistema de welfare", nestes casos, é tão-somente complementar às instituições de mercado. A Alemanha talvez fosse, hoje, o caso que mais se aproxima deste modelo (Fiori, 1997, p. 135).

Titmuss faz, como se percebe, a caracterização de dois tipos gerais em que o referencial é o mercado, seja por sua falha, seja por sua insuficiência. Adiante, seu tipo meritocrático-particularista tem desdobramentos à luz da experiência italiana. Nas palavras de Fiori:

Mais tarde, Ugo Ascoli (1984) tentou aumentar a precisão deste modelo, diferenciando dois subtipos seus: o "corporativo" onde o peso dos sindicatos e corporações na delimitação e distribuição dos benefícios é maior do que no "clientelístico" onde o peso maior se desloca para o sistema partidário e submete-se mais diretamente aos ciclos político-eleitorais (Fiori, 1997, p. 135).

Por fim, Titmuss completa sua tipologia com o modelo que se consagrou como universalista - the redistributive model of social policy -, quando o mérito do trabalho dá lugar ao valor da cidadania. Esse modelo, presente nos países nórdicos, especialmente na Suécia, pode ser identificado, segundo Fiori (1997), como "padrão institucional redistributivo, "voltado para a produção e distribuição de bens e serviços 'extramercado', os quais são garantidos a todos os cidadãos universalmente cobertos e protegidos" (Fiori, 1997, p. 136).

Fiori traz Esping-Andersen, que, a despeito de não se diferenciar substancialmente de Titmuss, "propôs uma nova nomenclatura para uma tipologia que agora chamou de 'regimes de welfare state'" (Fiori, 1997, p. 136).

A distinção de Esping-Andersen é que o critério utilizado em sua tipologia é o projeto político implícito em cada regime de welfare state. Por isso, ele intitula (1) welfare state liberal, (2) welfare states conservadores e fortemente corporativistas e (3) regimes social-democratas. No primeiro tipo, encontrado em Estados Unidos, Canadá e Austrália, "predominam a assistência aos comprovadamente pobres, reduzidas transferências universais ou planos modestos de previdência social e onde as regras para habilitação aos benefícios são estritas e muitas vezes associadas ao estigma" (Fiori, 1997, p. 136). O segundo modelo é encontrado em França, Alemanha, Itália e Áustria, e "predomina a preservação das diferenças de status; os direitos, portanto, aparecem ligados à classe e aos status [...] e a ênfase estatal na manutenção das diferenças de status significa que seu impacto em termos de redistribuição é desprezível". O último modelo, por seu turno, é aquele no qual "o universalismo e a desmercantilização atingem amplamente a classe média e 'onde todos os segmentos sociais são incorporados'” (Fiori, 1997, p. 137).

Mais adiante, no entanto, referindo-se a estudos posteriores, como veremos em Draibe, Fiori menciona os "filões mais ricos da hoje vasta literatura sobre o welfare state", e, recorrendo antes a Santos e seu conceito de cidadania regulada, reconhece um tipo de Ebes no Brasil: o meritocrático (Fiori, 1997, p. 137).

A gama de situações é de tal ordem que ainda poderíamos acrescentar a Fiori um tipo misto, em que se constitui, a nosso ver, o sistema educacional público no Brasil, reunindo universalismo (ensino fundamental e médio) e meritocracia (ensino superior).

Vianna (1991) se aproxima da conclusão de Fiori e é mais afirmativa, ao dizer que "na Itália e no Brasil os sistemas se enquadram com precisão na categoria meritocrático-particularista da tipologia Titmuss/Ascoli". Ela explica seu ponto de vista dizendo que "elementos conservadores se fizeram atuantes, nos dois, consolidando um estilo corporativista e hierarquizante de concessão de benefícios sociais" (Vianna, 1991, p. 146). 
A autora retoma a afirmação a partir da Constituição de 1988, tratando do artigo que dispõe sobre a seguridade social, vendo nisso a superação do limite meritocrático-particularista. Em suas palavras, "hoje, pelo artigo 194, a Seguridade Social, [...] estende a cidadania, conferindo direitos sociais a todo o povo brasileiro. Institucionaliza-se, enfim, o Estado do Bem-Estar Social. Supera-se, por força de lei, o particularismo do acesso corporativizado aos benefícios" (Vianna, 1991, p. 151).

Draibe (1993), em O welfare state no Brasil: características e perspectivas, diz que, "entre os anos trinta e a década de setenta, constituiu-se e consolidou-se institucionalmente, no Brasil, o estado social" (Draibe, 1993, p. 19). Na página anterior, a autora sintetiza as formas de realização do Ebes, em quadro de sua elaboração significativamente intitulada Morfologia do welfare state no Brasil" (Draibe, 1993, p. 18). Refletindo sobre "a periodização do welfare state, afirma ainda que cabe "examinar criteriosamente a natureza da produção legal e inovações em políticas que transcorrem dos anos 30 até agora, de modo a evitar uma visão linear do movimento de construção e consolidação do welfare state entre nós" (Draibe, 1993, p. 19).

Draibe reconhece a polêmica sobre o Ebes no Brasil. Ela afirma que "estudos e debates sobre as políticas sociais no Brasil [adquiriram] forte tonalidade negativa, referidos a um oposto - o welfare state - tomado [...] como especialidade anglo-saxã no campo da social policy" (Draibe, 1993, p. 2). A seguir, acrescenta que "é possível apreender o Estado Protetor menos como a concretização de programas social-democratas do pós-guerra, antes como elemento estrutural importante das economias capitalistas contemporâneas, uma forma de articulação entre o Estado e o mercado, o Estado e a sociedade" (Draibe, 1993, p. 2).

Na mesma direção, Fleury (1985), ao tratar de política social, considera que há 3 modalidades principais de proteção social que acompanham o desenvolvimento histórico do Estado Moderno: "assistência social, seguro social e estado de bem-estar social [...]. No caso brasileiro, o que tenho demonstrado é a existência das três modalidades apontadas" (Fleury, 1985, pp. 401-403).

Lobato (2016), a exemplo de Vianna, toma a Constituição de 1988 como "um capítulo específico para a ordem social” (Lobato, 2016, p. 90). Segundo ela, "a seguridade social institucionaliza um modelo ampliado de proteção social, nos moldes dos estados de bem-estar social". É a mesma compreensão de Crestani e Oliveira (2018), para quem, "considerando a Constituição/88 como um referencial de mudanças, pode-se identificar que, a partir de então, o Estado brasileiro começou a deixar para trás o modelo conservador e corporativista, aproximando-se do tipo de estado de bem-estar social-democrata" (Crestani \& Oliveira, 2018, p. 318). É também esse o entendimento de Menicucci e Gomes (2018), que atribuem à Constituição de 1988 a transição de um modelo de seguro social para o de seguridade, elevando o patamar de cidadania.

Considerando as classificações de Esping-Andersen e Titmus, o que dizem os autores brasileiros acima mencionados e a observação da realidade construída antes e principalmente após a Constituição de 1988, inclinamo-nos a reconhecer a existência de uma combinação de expressões do welfare state que representaram conquistas, ganhos, acessos, direitos e garantias desenvolvidos ao longo do tempo, tributários de lutas, pressões, negociações, concessões, crises, temores e solidariedade.

\section{O ISSB E A CARTA DA PAZ SOCIAL}

Segundo as correntes em que se dividem as explicações para a iniciativa inglesa, há diferentes causas do welfare state. Para uns, a pressão dos sindicatos e dos partidos do trabalho (Esping-Andersen, 1991; Rosanvallon, 1997); para outros, os problemas estruturais do modo de produção, cuja instabilidade exige a intervenção estatal para garantir o nível de consumo e o pleno emprego (O'Connor, 1977; Offe, 1984; Przeworski, 1991). Assim como podemos entender a imbricação dos tipos, podemos apreender a complexidade das causas.

A essas razões, de duplo entendimento, poderíamos acrescer outro aspecto, relacionado à política internacional e à necessidade de obter a unidade nacional para ela. O Relatório Beveridge, origem formal da proposta do welfare state, se constrói em contexto de guerra, em 1942, sob a lembrança do conflito de 1914-1919, quando as organizações socialistas rejeitavam a guerra, tratavam-na como assunto fora do interesse dos trabalhadores, classificavam-na como uma luta entre frações burguesas e condenavam as verbas destinadas ao conflito. Ilustrando isto, Lênin, certamente um autorizado representante da ala radical social-democrata, porta-voz desse sentimento, dizia que "o sentido da guerra presente é anexar terras e subjugar outras nações [...] desviar a atenção das massas trabalhadoras das crises políticas internas [...] desunir e confundir os operários com propaganda nacionalista e exterminar a sua vanguarda para debilitar o movimento revolucionário" (Lênin, 1976, p. 161). 
Oposições como essa se repetiram na Alemanha, na Inglaterra e na França, dificultando a arregimentação de forças e a aprovação das verbas de guerra no primeiro grande conflito. $O$ temor de que algo parecido se repetisse, recriando a perspectiva da dissidência interna e da própria revolução social, a exemplo do que então ocorrera na Rússia, fez-se presente naquele momento. Além disso, na Inglaterra, sob a liderança de Oswald Mosley e seu British Union of Fascists (BUF), também evoluíam propostas nazifascistas dirigidas aos trabalhadores, que igualmente preocupavam os conservadores (Colin, 1961; Silva, 2017). Não é sem razão, portanto, que em 1941 a Carta do Atlântico, elaborada por Churchill e Roosevelt, e imediatamente apoiada por outros países, apontava para medidas sociais a serem adotadas após a guerra (Marshall, 1967; Sigerist, 1944). A singularidade europeia do processo não deve ser subestimada quando relembramos o Relatório e o Plano Beveridge. As circunstâncias vividas pelos países da Europa, em particular pela Inglaterra, aconselhavam o esforço pela construção de ampla aliança que incluísse claramente os trabalhadores. De sua parte, os Estados Unidos estavam saindo de uma profunda crise, tendo também para isso feito um "novo acordo/new deal", incluindo os trabalhadores de modo explícito.

O Relatório e o Plano Beveridge são a declaração mais completa dessa movimentação por um pacto de classe. Seus 3 princípios e recomendações diziam:

O primeiro princípio é que quaisquer propostas para o futuro, embora devam usar ao máximo a experiência adquirida no passado, não devem ser restringidas a ela. Neste momento, quando a guerra está abolindo marcos de todo tipo, é a oportunidade clara para inovar. Um momento revolucionário na história do mundo é um momento para revoluções, não para remendos.

O segundo princípio é que a organização do plano de seguridade social deve ser tratado como apenas uma parte de uma política abrangente do progresso social. Um plano de seguridade social totalmente desenvolvido pode fornecer segurança financeira; é um ataque à Pobreza. Mas Pobreza é apenas um dos cinco gigantes no caminho da reconstrução e, de certa forma, o mais fácil de atacar. Os outros são Doença, Ignorância, Miséria e Ociosidade.

O terceiro princípio é que a seguridade social deve ser alcançada pela cooperação entre o Estado e o indivíduo. $\mathrm{O}$ Estado deve oferecer seguridade para serviço e contribuição. O Estado, ao organizar a seguridade, não deve sufocar incentivos, oportunidades, responsabilidades; ao estabelecer um mínimo nacional, deve haver espaço e incentivo para a ação voluntária de cada indivíduo para fornecer mais do que esse mínimo para si e sua família (Fordham University, 1942, p. 1).

O Estado, para cumprir seu papel descrito no terceiro princípio, lança mão de fontes de arrecadação que são mais uma vez a demonstração da aliança construída sob o princípio de todos os princípios: a solidariedade. Isso se confirma quando Beveridge explica as duas fontes principais do Seguro Social: "Pela contribuição, o mais pobre e o mais rico dos homens são tratados igualmente. [...] Pelo imposto, ao contrário, o mais rico, em virtude da sua capacidade de pagar, paga mais para os fins gerais da comunidade" (Beveridge, 1943, p. 170).

O Relatório e o Plano Beveridge repercurtiram em todo o mundo. No Brasil, há registros de maior divulgação no Jornal do Commercio, em 1944 (Gonçalves, 2001). Mas antes, em 1943, a José Olympio, editora sediada no Rio de Janeiro, então capital da República, publicou o documento O Plano Beveridge: relatório sobre o Seguro Social e Serviços Afins (Beveridge, 1943). Além disso, técnicos do governo brasileiro participaram de encontros internacionais sobre as políticas sociais, em particular sobre o Plano Beveridge, cuja popularidade o fazia tema de debates e artigos (Assis, 1950).

É nesse momento, ao fim da guerra, sob variadas circunstâncias e tensões políticas, que Vargas, atento aos desdobramentos políticos nacionais e internacionais, editou o Decreto $n^{\circ} 7.526$, de 7 de maio de 1945 , dispondo sobre a criação do Instituto de Serviços Sociais do Brasil, o ISSB.

Malloy (1976), professor da Universidade de Pittsburgh, em artigo na Revista de Administração Pública, traz o seguinte comentário sobre o ISSB:

Muito importante para o esquema foi a criação de um novo tipo de instituto denominado Instituto de Serviço Social Brasileiro - ISSB. O esquema incluía um plano global de proteção do berço ao túmulo, baseado em: I) assistência médica ampla; 2) uma gama completa de programas assistenciais; 3) os tradicionais benefícios de aposentadoria e pensões (Malloy, 1976, p. 15). 
As metas do instituto são destacadas pelo articulista para ilustrar sua alusão ao welfare state:

Os idealizadores do ISSB, fortemente influenciados pelo Plano Beveridge, da Inglaterra, visavam a três metas principais adicionais: 1 ) estender a proteção da previdência social a todo brasileiro (constituindo as duas únicas exceções os servidores públicos civis e militares, que conservariam seus próprios sistemas), incluindo, naturalmente, os trabalhadores rurais, que até então não tinham assistência; 2) o ISSB estabeleceria um plano uniforme de contribuições e benefícios para todos; 3) todas as atividades da previdência social seriam unificadas sob um único instituto, o ISSB (1976).

Nessa passagem, além de vários aspectos importantes, chama a atenção o fato de que, mais uma vez, a referência a Beveridge e seu plano aparece no cenário da previdência e assistência social brasileiras.

É necessário observar ainda que o comentário de Malloy sobre a extensão do ISSB - "do berço ao túmulo" - segue o próprio Plano Beveridge em sua "característica principal": "a principal característica do Plano de Previdência Social é um regime de seguro social contra interrupção ou destruição do poder aquisitivo e para despesas especiais decorrentes de nascimento, casamento ou morte" (Fordham University, 1942, p. 5). Confirmava-se, também no caso brasileiro, sua determinação de ser um plano amplo, de cobertura completa, revolucionário, not for patching.

Vargas, em discurso que exaltava sua própria iniciativa, aludiu mais uma vez a Beveridge, dizendo que, "com esse plano, colocava-se o Brasil novamente na liderança dos sistemas de previdência social, antecipando e superando-as em muitos pontos as reformas no mesmo sentido empreendidas em outras nações [...] inclusive o famoso Plano Beveridge, na Inglaterra" (1952). O ISSB não evoluiu, mas a presença da questão social no espelho do Plano Beveridge voltaria no início do segundo governo de Vargas, com a Comissão Nacional de Bem-Estar Social, que funcionaria de 1951 a 1954 (Oliveira, 2020).

Em paralelo aos acontecimentos que envolviam o Plano Beveridge e o ISSB, desenvolvia-se entre os empresários brasileiros um movimento que guardava o mesmo espírito de conciliação: a I Conferência das Classes Produtoras (Conclap), ocorrida em 1945. Nela, além da Carta Econômica de Teresópolis, "aprovou-se a Carta da Paz Social, documento que deu forma à filosofia e ao conceito de serviço social custeado pelo empresariado" (Centro de Pesquisa e Documentação de História Contemporânea do Brasil [CPDOC], 2009).

Estiveram presentes 183 delegações, e entre as figuras mais representativas encontravam-se os empresários Brasílio Machado Lopes e João Daudt de Oliveira, ambos do comércio; Iris Meinberg, da agricultura; e Roberto Simonsen e Euvaldo Lodi, da indústria. Incontestavelmente, eram os maiores líderes dos setores à época. As "classes produtoras" pretendiam "unir forças em favor do desenvolvimento" e superar "um grande entrave para essa conquista", a pobreza, os conflitos sociais, "principalmente entre empregadores e empregados", como se lê na apresentação da Carta da Paz Social (Serviço Social do Comércio [Sesc], 2012).

Na abertura, lê-se:

Os empregadores e empregados que se dedicam, no Brasil, aos vários ramos de atividade econômica reconhecem que uma sólida paz social, fundada na ordem econômica, há de resultar precipuamente de uma obra educativa, por meio da qual se consiga fraternizar os homens, fortalecendo neles os sentimentos de solidariedade e confiança. Reconhecem a necessidade de assegurar dentro do país um largo período de cooperação para que se possa processar o desenvolvimento de suas forças produtivas e a elevação do padrão de vida do brasileiro (Sesc, 2012, p. 11).

Após essa declaração de intenção, anunciam-se as iniciativas e os compromissos:

Para isso é indispensável promover o aumento da renda nacional e sua melhor e mais vasta distribuição, com o melhor aproveitamento dos recursos do país, o qual poderá ser obtido pondo em execução um planejamento econômico amplo e objetivo, nos termos da Carta de Teresópolis. Com esse propósito, e na convicção de que nada será conseguido sem o mais estreito entendimento entre empregadores e empregados [...] solenemente assumem o compromisso de propugnar a consecução desses objetivos (Sesc, 2012, p. 11). 
A Carta Econômica de Teresópolis, referida nessa citação como Carta de Teresópolis, é o documento geral da I Conclap. Segundo o site da FGV CPDOC, no tópico "Política social" dessa Carta se diz que "a população deveria receber assistência médica e ensino especializado primário e secundário, [...] até a idade de 14 anos. Do mesmo modo, o seguro social deveria estender-se a toda população, sendo suas reservas destinadas à construção de escolas, hospitais e moradias para os segurados (CPDOC, 2019).

No particular da Carta da Paz Social, ali se lê que "o capital não deve ser considerado apenas instrumento produtor de lucro, mas, principalmente, meio de expansão econômica e bem-estar coletivo" (Sesc, 2012, p. 12). Seus itens 7 e 8 reúnem, respectivamente, compromissos e prescrições para empregadores e empregados, no sentido de, com seus meios, contribuírem em conjunto para os objetivos anunciados. No item 10, consta que, "completando o conjunto de medidas constantes desta Carta, empregadores e empregados farão sentir ao Estado a necessidade das seguintes providências", seguindo-se medidas nos planos monetário, fiscal e administrativo que caberiam ao Estado implementar (Sesc, 2012, pp. 14-16). Quanto à aplicação dos recursos da previdência, reafirma-se que as classes produtoras "pensam ser de justiça destinar a empreendimentos de nítido interesse coletivo as reservas financeiras do seguro social, especialmente à construção de escolas e hospitais, e bem assim, de casas para os segurados" (CNI/Conclap, 1945, p. 15).

Fazem parte da agenda social proposta a adoção do sistema de férias coletivas e a instalação de colônias de férias. Além disso, "congregar suas energias no sentido de contribuir para o melhoramento da educação e da saúde do brasileiro" (CNI/Conclap, 1945, p. 16) e a instalação de restaurantes populares (CNI/Conclap, 1945, p. 24). Atribuindo essas demandas ao Estado, os empresários, entretanto, no espírito da época, também se comprometem. Na Carta da Paz Social, "propõem-se os empregadores a criar um Fundo Social a ser aplicado em obras e serviços que beneficiem os empregados de todas as categorias, e em assistência social em geral". Aprofundando o compromisso, definem que "o Fundo Social será constituído por uma contribuição de cada empresa - agrícola, industrial e comercial, ou de outra natureza —, retirada dos lucros líquidos de seu balanço" (Sesc, 2012, p. 13).

Por fim, como observa Delgado (2007), em artigo sobre o empresariado e as políticas sociais no Brasil,

ainda que restritas, se confrontadas com as reivindicações de diversas categorias profissionais e com proposições de grupos dentro do Estado, as formulações da Carta Econômica de Teresópolis sobre a política social revelam uma crescente aceitação, pelos empresários, da ampliação do sistema público de proteção social [...] a sugestão de generalização do seguro social e de unificação dos institutos de previdência aproximava-se das formulações universalistas que ganhavam influência com a divulgação do Relatório Beveridge na Inglaterra. Em seu conjunto, portanto, a Carta Econômica de Teresópolis revela um empresariado disposto a aceitar a intensificação da ação protetora do Estado, de modo a superar as "incompreensões e mal-entendidos" (Delgado, 2007, pp. 150-151).

É verdade que a Carta da Paz Social é pragmática e, em certa medida, autoritária. Nela está explícito que suas promessas e intenções se dão "não só por motivo de solidariedade social, mas de conveniência econômica" (Sesc, 1971, p. 12), incentivar a produtividade individual", determinar "que os dissídios sejam resolvidos Cobra-se uma postura igualmente conciliadora dos trabalhadores, porque lhes pede desde "d) cooperar para que reine a necessária disciplina na execução do trabalho", passando por "f) procurar primeiramente nas comissões mistas sindicais" e arrematando que "[...] quaisquer direitos sejam reivindicados por meios pacíficos, condenando-se formalmente todo o recurso à violência" (Sesc, 1971, p. 16). Essas formulações parecem óbvias e razoáveis. No entanto, sabe-se, pelo histórico anterior, recente e presente, que sua aplicação tem nuances bastante autoritárias. Mas, igualmente sem dúvida, é possível considerar a Carta Econômica de Teresópolis e a Carta da Paz Social 2 testemunhos da tentativa de construção no Brasil de um projeto social ao estilo daquilo que se via na Inglaterra, com o apoio amplo das sociedades civil e política. Cabe essa avaliação sobretudo no que tange ao tripé de sustentação da seguridade trabalhadores, empregadores e Estado - e no que diz respeito à sua extensão intencionalmente ampla, elementos que, relembrando Esping-Andersen, fazem a distinção entre as políticas sociais anteriores ao pós-guerra e ao welfare state. 


\section{CONCLUSÃO}

A chamada questão social, que se estende aos nossos dias e vive agora momentos muito especiais, tem no estado de bem-estar social uma referência forte. O welfare state, de origem inglesa, apresentou-se ao mundo, desde seu nascimento, como um passo avançado, um projeto revolucionário, como o classificava seu principal formulador, Lord Beveridge.

Tratou-se de um plano mantido pela contribuição da sociedade, na forma de tributos e contribuições pagos por todos, seja por empregadores ou empregados, seja pelo Estado. Falamos de sociedade porque as contribuições e os impostos dos empregadores nunca deixaram de ser repassados aos preços, cabendo-nos a todos pagá-los. Por sua vez, o Estado não dispõe de recursos próprios, senão em operações de emissão. Sua receita primária são os tributos, que vêm da sociedade.

Assim constituído, o Plano Beveridge, que deu origem ao welfare state, inaugurou um esquema amplo de sustentação fiscal e de cobertura, tendo em foco o trabalhador, em suas formas variadas, inclusive as donas de casa, tendendo a acolher o cidadão, universalmente, como viria a acontecer.

Dois aspectos se destacam nessa descrição: 1) a solidariedade, motivada por variadas razões, quando, segundo vimos em Santos, "a soberania nacional, a democracia e a justiça social e a confiança na unidade do gênero humano serviam de princípios comuns para reordenar o mundo"; e 2) a generosidade, no duplo sentido que essa palavra pode ter no contexto, ou seja, o sentimento de que se construía um novo mundo, "não um remendo", como escreveu Beveridge, e que nesse novo mundo não havia lugar para a mesquinhez e a exclusão.

No Brasil, o tema do welfare é tratado por duas leituras: a primeira, que se tornou mais conhecida, afirma sua inexistência em nossa história; a segunda considera que há semelhanças no sistema brasileiro, acompanhando o cenário internacional, mas especialmente a partir da Constituição de 1988. Nesse último caso, haveria uma combinação de políticas restritas com políticas universais, generosas, estas configuradas no texto constitucional.

Os fatos históricos resgatados mostram que as políticas sociais do pós-Segunda Guerra, seja na Inglaterra, seja no Brasil, seguiram traços similares e passos próximos: tentativa de resgate do capitalismo como projeto de desenvolvimento econômico-social, busca da conciliação de classes, preocupação com os desdobramentos políticos do avanço da democracia e do socialismo, atenção às necessidades básicas dos segmentos de baixa renda e intenção/pretensão de ampla cobertura, "no nascimento, casamento ou morte" (Beveridge), "do berço ao túmulo" (ISSB).

Esse é o primeiro ângulo do debate que se quer, aqui, colocar em evidência. Isso tem importância porque corresponde às necessidades estruturais do capital, uma vez consideremos dialeticamente que as contradições do modo de produção, as pressões e lutas dos trabalhadores, os problemas do consumo, do investimento e do pleno emprego - conjunto de causas explicativas do Welfare State -, na verdade, são uma unidade a que, respeitando as singularidades nacionais, todo o capitalismo do pós-guerra se viu atado.

O segundo ângulo é que, desde o advento da crise do capital, dos anos 1970 e principalmente nos anos 1990, seguiu-se um processo de redução do estado de bem-estar social, sob a alegação de limitações fiscais, mas também em nome da restauração dos valores do mercado, inclusive seu poder autorregulador. Enquanto esse poder não se apresenta, pretende-se superar a persistente crise de superacumulação por via dos ativos físicos/econômicos e dos fundos públicos, que continuam a ser cada vez mais mobilizados, em privatizações, concessões, renúncias fiscais, créditos subsidiados e investimentos em infraestrutura. São vias tradicionais de enfrentamento das crises, sob certa óptica. Pende de resposta, portanto, a questão muito razoável que se pode fazer sobre quanto as preocupações do pós-guerra, relacionadas aos problemas estruturais e sociais, foram superadas. A resposta que se está configurando, à luz das condições de desigualdade de renda e de riqueza crescentes, associadas à redução da seguridade pública, é que esses problemas não só continuam, como seu tratamento não se está dando pelo caminho das políticas sociais universais. As preocupações e, pior, o "espírito de Dunquerque" estão sendo relegados.

Afastadas as aflições políticas, em face da fragilidade dos sindicatos obreiros e dos partidos do trabalho, os "princípios comuns para reordenar o mundo", soberania nacional, democracia, justiça social e a confiança na unidade do gênero humano parecem não mais fazer parte da lógica nem do discurso de grande parte das lideranças empresariais e políticas. Em médio prazo, enquanto a histoire conjunturelle, para usar uma expressão de Braudel, não se alterar em seus elementos principais, não devemos esperar nada igual ao Plano Beveridge, ao ISSB ou à Carta da Paz Social, porque a unidade das causas que levaram 
à revolução passiva carece hoje de sua dimensão política, sem a qual a dimensão econômica, exclusivamente, não é capaz de levar a qualquer reforma no conceito progressista que tem essa palavra.

Por fim, temos agora a certeza de que, a despeito de não podermos dizer, como Vargas, que fomos além de Beveridge ou que chegamos próximos, os brasileiros de menor renda, os trabalhadores, as chamadas camadas médias, tiveram e ainda têm algo a perder. Políticas previdenciárias e assistenciais; de proteção a idosos, crianças, adolescentes, mulheres e segmentos mais vulneráveis; além de educação e saúde públicas, são valores públicos que serviram e servem a milhões. Sua existência deficiente se presta a melhoras, correções e aperfeiçoamentos. Sua supressão, não. Defendê-los é mais que razoável, em particular quando a desigualdade e suas consequências pedem atenção. Parte dessa atenção é a reabilitação da solidariedade como um elemento constitutivo, estrutural, da sociabilidade. 


\section{REFERÊNCIAS}

Assis, A. (1950). Preservamos a nossa previdência Social. Revista Brasileira de Seguridade Social, 2(2), 16-32.

Beveridge, W. (1943). Relatório sobre o Seguro Social e Serviços Afins. Rio de Janeiro, RJ: José Olympio.

Carvalho, J. M. (2013). Cidadania no Brasil. O longo caminho. Rio de Janeiro, RJ: Editora Civilização Brasileira.

Centro de Pesquisa e Documentação de História Contemporânea do Brasil. (2009). I CONCLAP Carta da Paz Social. Recuperado de http://www.fgv.br/CPDOC/ACERVO/dicionarios/verbete-tematico/ servico-social-do-comercio-sesc

Centro de Pesquisa e Documentação de História Contemporânea do Brasil. (2019). Carta Econômica de Teresópolis. Recuperado de http://www.fgv.br/Cpdoc/Acervo/dicionarios/verbetetematico-conferencia-nacional-das-clas ses-produtoras-i-i-conclap Colin, C. (1961). The fascists in Britain. New York, NY: St Martin's.

Conferência das Classes Produtoras do Brasil. (1945). Carta Econômica de Teresópolis. Rio de Janeiro, RJ: CNI.

Crestani, D., \& Oliveira, C. (2018). Que tipo de estado de bem-estar social é este? Revista Eletrônica Científica da UERGS, 4(2), 299-319.

Delgado, I. (2007). O Empresariado Industrial e a Gênese das Políticas Sociais Modernas no Brasil Industrial. Locus: revista de história, 13(2), 135-160.

Draibe, S. M. (1993). O Welfare State no Brasil: características e perspectivas. Campinas, SP: Unicamp.

Draibe, S. M., \& Henrique, W. (1988). "Welfare state", crise e gestão da crise: um balanço da literatura internacional. Revista Brasileira de Ciências Sociais, 3(6), 53-78.

Ellman, M. (1980). Planejamento socialista. Rio de Janeiro, RJ: Zahar. Esping-Andersen, G. (1991). The Three Worlds of Welfare Capitalism. New Jersey, NY: Princeton University Press.

Faleiros, V. P. (1991). O que é Política Social. São Paulo, SP: Brasiliense.

Fiori, J. L. (1997). Estado de Bem-Estar Social: padrões e crise. Physis - Revista de Saúde Coletiva, 7(2), 129-147.

Fleury, S. (1985). Política social e democracia: reflexões sobre o legado da seguridade social. Cad. Saúde Pública, 1(4), 400-417.

Fordham University. (1942). Modern History Sourcebook: Sir William Beveridge: Social and Allied Services (The Beveridge Report). Recuperado dehttps://sourcebooks.fordham.edu/mod/1942beveridge.asp.

Gonçalves, M. (2001). O Plano Beveridge e o Sistema de Bem-Estar Social no Brasil 1945-1954 (Trabalho de Conclusão de Curso). Universidade Estadual Paulista, Araraguara, SP.

Gramsci, A. (2007). Quaderni del carcere: edizione critica dell'Istituto Gramsci a cura di Valentino Gerratana, Torino, Italy: Einaudi.

Hilferding, R. (1981). Finance Capital - A study of the latest phase of capitalist development. Abingdon, UK: Routledge.

Jansen Ferreira, M., \& Mendes, A. (2018). Mercantilização nas reformas dos sistemas de saúde alemão, francês e britânico. Ciênc. Saúde coletiva, 23(7), 2159-2170.
Kalecki, M. (1978). Teoria da Dinâmica Econômica. São Paulo, SP: Abril Cultural.

Kerstenetzky, C., \& Guedes, G. (2018). O Welfare State resiste? Desenvolvimentos recentes do estado social nos países da OCDE. Ciência \& Saúde Coletiva, 23(7), 2095-2106.

Kondratiev, N. (1979). The long wave in economic life. The Review of Economics and Statistics, 2(4), 105-115.

Lenin, V. (1976). A guerra y la socialdemocracia de Rusia. In V. Lenin (Org.), Obras escogidas en doce tomos (tomo V). Moscou, RU: Progreso.

Lobato, L. (2016). Políticas sociais e modelos de bem-estar social: fragilidades do caso brasileiro. Saúde Debate, 40(esp.), 87-97.

Malloy, J. (1976). Política de bem-estar social no Brasil: histórico, conceitos, problemas. Revista de Administração Pública, 10(2), 5-29.

Marshal, T. (1967). Cidadania, classe social e status. São Paulo, SP: Zahar.

Menicucci, T., \& Gomes, S. (2018). Políticas sociais: conceitos, trajetórias e a experiência brasileira. Rio de Janeiro, RJ: Editora Fiocruz.

Mishra, R. (1990). The Welfare State in Capitalist Society: Policies of Rentrenchment and Maintenance in Europe, North America and Australia. Toronto, Canada: University of Toronto Press.

Oliveira, S. S. R. (2019). A Comissão Nacional de Bem-estar Social: planejamento estatal e política social, 1951-1954. História, Ciências, Saúde-Manguinhos, 26(1), 147-161.

Pastor Seller, E., Verde Diego, C., \& Lima Fernandez, A. I. (2019). Impact of neo-liberalism in Spain: research from social work in relation to the public system of social services. European Journal of Social Work, 22(2), 277-288.

Piana, M. C. (2009). A construção do perfil do assistente social no cenário educacional. São Paulo, SP: Cultura Acadêmica.

Rosanvallon, P. (1997). A Crise do Estado Providência. Goiânia, GO: Editora da UFG.

Santos, T. (2004). Do terror à esperança. São Paulo, SP: Ideias \& Letras.

Serviço Social do Comércio. (2012). Carta da Paz Social. Rio de Janeiro, RJ: SESC.

Sigerist, H. (1943). From Bismarck to Beveridge: Developments and Trends. Journal of Public Health Policy, 20(4), 474-496.

Silva, J. P. (2017). A British Union of Fascists e o fascismo internacional através do periódico blackshirt (193-1939). Recuperado de http://www.cih.uem.br/anais/2017/trabalhos/4014.pdf

Silva, R. (2011). Do welfare ao workfare ou da política social keynesiana / fordista à política social schumpeteriana / pós-fordista. Revista Ser Social, 13(28), 104-128.

Soares, E. (2020). O fracasso do Bem-Estar Social na democracia brasileira. Revista Serviço Social em Perspectiva, 4(esp.), 915-928.

Stein, R. H. (2017). La protección social en América Latina y la particularidad de la asistencia social. Revista Ser Social, 19(40), 49-68.

Streck, L., \& Morais, J. (2006). Ciência política \& teoria do Estado. Porto Alegre, RS: Livraria do Advogado Editora. 
Titmus, R. (1963). Essays on the Welfare State. Londres, UK: Allen \& Unwin.

Vargas, G. (1952). Tópicos da mensagem do chefe de governo. Industriários, 32, 27-39.
Vianna, M. L. W. (1991). Notas sobre política social. Physis Revista de Saúde Coletiva, 1(1), 133-159.

Wolff, P., \& Oliveira, G. (2017). O "espírito de Dunquerque" e o NHS inglês: teoria, história e evidências. Revista tempo do mundo, 3(2), 193-241.

Claudio Gurgel

ORCID: https://orcid.org/0000-0003-4840-9772

Economista; Especializado em administração de empresas; Mestre em administração pública; Mestre em ciência política e doutor em educação; Professor Titular da Faculdade de Administração e Ciências Contábeis da Universidade Federal Fluminense (UFF); Membro do corpo permanente do Programa de Pós-Graduação em Administração (PPGAd/UFF). E-mail: crmgurgel@hotmail.com

Agatha Justen

ORCID: https://orcid.org/0000-0002-6191-7942

Cientista social pela Universidade Federal do Rio de Janeiro (UFRJ); Mestre em administração (FGV EBAPE); Mestre em políticas públicas, estratégias e desenvolvimento pela Universidade Federal do Rio de Janeiro (UFRJ); Doutora em administração (FGV EBAPE); Professora adjunta do departamento de administração da Universidade Federal Fluminense (UFF); Coordenadora do Curso de Administração Pública e docente permanente do Programa de Pós-Graduação em Administração (PPGAd/UFF). E-mail: agatha_justen@hotmail.com 